Research Paper: Gerotarget (Focus on Aging)

\title{
Baicalein protects against oxLDL-caused oxidative stress and inflammation by modulation of AMPK- alpha
}

\author{
Kun-Ling Tsai 1,*, Ching-Hsia Hung1,2,*, Shih-Hung Chan ${ }^{3}$, Jhih-Yuan Shih4, Yung- \\ Hsin Cheng ${ }^{5}$, Yi-Ju Tsai ${ }^{1}$, Huei-Chen Lin ${ }^{2,6}$ and Pei-Ming Chu ${ }^{7}$ \\ ${ }^{1}$ Department of Physical Therapy, College of Medicine, National Cheng Kung University, Tainan, Taiwan \\ 2 Institute of Allied Health Sciences, College of Medicine, National Cheng Kung University, Tainan, Taiwan \\ 3 Department of Internal Medicine, National Cheng Kung University Hospital, College of Medicine, National Cheng Kung \\ University, Tainan, Taiwan \\ ${ }^{4}$ Department of Internal Medicine, Chi-Mei Hospital, Tainan, Taiwan \\ ${ }^{5}$ Department of Education and Research, Taipei City Hospital, Taipei, Taiwan \\ ${ }^{6}$ Department of Physical Therapy, Shu-Zen Junior College Of Medicine And Management, Taiwan \\ ${ }^{7}$ Department of Anatomy, School of Medicine, China Medical University, Taichung, Taiwan \\ * These authors have contributions equally to this work
}

Correspondence to: Pei-Ming Chu, email: pmchu@mail.cmu.edu.tw

Keywords: atherosclerosis, ROS, endothelial cells, lectin-like oxidized LDL receptor 1, baicalein, Gerotarget

Received: July 06, $2016 \quad$ Accepted: October 13, $2016 \quad$ Published: October 20, 2016

\section{ABSTRACT}

Atherosclerosis is considered to be a form of chronic inflammation and a disorder of lipid metabolism. Oxidative transformations in the lipid and apolipoprotein B (Apo B) constituent of low density lipoprotein drive the initial step in atherogenesis due to macrophage scavenger receptors identify oxidized LDL (oxLDL) but nonoxidized LDL. The human vascular endothelial cells fact a critical role in vasodilation, provides a nonadhesive surface for circulation, reduces vascular smooth muscle proliferation, inflammation, thrombus formation and platelet aggregation. Assembly of oxLDL contribute to stimulation of endothelial cells with up-regulation of adhesion molecules, increase oxidative stress to the vascular endothelium and inhibition of NOmediated vasodilation. When adhesion molecules are over-expressed on the surface of endothelial cells under oxLDL stimulation, it will recruit monocytes to the arterial wall. Then adherent monocytes will migrate into the subendothelial space and subsequently differentiate into macrophages. In the subendothelial space, oxLDL will be taken up by macrophages, thereby causing the substantial cholesterol accumulation and the foam cells production.

\section{INTRODUCTION}

Atherosclerosis is considered to be a form of chronic inflammation and a disorder of lipid metabolism [1]. Oxidative transformations in the lipid and apolipoprotein B (Apo B) constituent of low density lipoprotein drive the initial step in atherogenesis due to macrophage scavenger receptors identify oxidized LDL (oxLDL) but non-oxidized LDL [2]. The human vascular endothelial cells act a critical role in vasodilation, provides a nonadhesive surface for circulation, reduces vascular smooth muscle proliferation, inflammation, thrombus formation and platelet aggregation [3]. Assembly of oxLDL contribute to stimulation of endothelial cells with up-regulation of adhesion molecules, increase oxidative stress to the vascular endothelium and inhibition of NOmediated vasodilation [4]. When adhesion molecules are over-expressed on the surface of endothelial cells under oxLDL stimulation, it will recruit monocytes to the arterial wall. Then adherent monocytes will migrate into the subendothelial space and subsequently differentiate into macrophages [5]. In the subendothelial space, oxLDL will be taken up by macrophages, thereby causing the substantial cholesterol accumulation and the foam cells production [6]. 
Lectin-like Oxidized LDL receptor 1 (LOX-1), also known as scavenger receptor class E member 1 (SR-E1). It is expressed in vascular smooth muscle cells, macrophages and vascular endothelial cells $[7,8]$. Alike to other type of scavenger receptors, LOX-1 binds various ligands. Such as polyinosinic acid and phosphatidylserine [9], activated platelets [10]. LOX-1 has been revealed with the ability to bind oxLDL, but not native LDL [11]. A previous study revealed that oxLDL led to LOX-1 over-expression also activated NADPH oxidase (both gp91phox and p47phox subunits) expression and enhanced ROS generation in human coronary artery endothelial cells stimulated with. They proposed the evidence for the pathway use of antiLOX-1 antibody markedly reduced oxLDL-induced ROS generation and NADPH oxidase expression [12].

The AMP-activated protein kinase (AMPK) is one heterotrimeric serine/threonine protein kinase. AMPK is up-activated in many varied cell types by enhancing intracellular concentrations of AMP [13]. Several studies suggested that AMP-activated protein kinase (AMPK) is not only in controlling metabolic homeostasis but also in cardiovascular pathology. Moreover, Wang et al showed that AMPK $\alpha$ deficient mice increased the expression of p47phox, p67phox, and gp91phox compared to their wild type counterparts leading to enriched ROS generation and accelerated degradation of $\mathrm{I}-\mathrm{KB}$, resulting in excessive up-regulation of NF- $\kappa B$ and consequent NADPH oxidase activation [14]. They revealed that AMPK $\alpha$ functions as a physiological inhibitor of NADPH oxidase and ROS production in endothelial cells. Ceolotto et al also showed that endothelial cells incubated with a pharmacological activator of AMPK (AICAR) protects against high glucose-caused NADPH oxidase over-expression and ROS formation by PKC inhibition [15]. Therefore, AMPK maintains the anti-atherogenic and anti-inflammatory phenotype of human endothelial cells.

Baicalein is one natural phenolic antioxidant which is isolated from Scutellaria baicalensis (S. baicalensis) Georgi (Huangqinin Chinese). S. baicalensis Georgi is one extensively used herb employed in China and also in other countries. In traditional Chinese medicines, extracts from the Scutellaria radix have been applied for anti-cancer, anti-inflammation, repressing the cholesterol concentrations and repressing blood pressures $[16,17]$. In this study, we aimed to explore whether Baicalein could mitigate LOX-1-drived human endothelial dysfunction by the up-regulation of NADPH oxidase, and if so, whether AMPK was involved in the process.

\section{RESULTS}

\section{Effect of baicalein on LOX-1 protein expression induced by oxLDL}

LOX-1 binds structurally diverse ligands and oxLDL has been identified with the ability to bind LOX-1 [11]. The expression levels of LOX-1 protein expression in HUVECs were enhanced by oxLDL (150 $\mu \mathrm{g} / \mathrm{ml})$. Treatment of HUVECs with baicalein for $2 \mathrm{hrs}$ at concentrations above $2.5 \mu \mathrm{M}$ before exposure to oxLDL for $24 \mathrm{hrs}$ resulted in suppression of LOX-1 expression both in protein levels (Figure 1). In addition, pretreatment with a free radical inhibitor (DPI) significantly mitigates oxLDL-facilitated LOX-1 up-regulation.

\section{Effects of baicalein on oxLDL-induced NADPH oxidase activation}

Previous study has reported a predominant function of vascular NADPH oxidases in free radical formation. The effects of baicalein on gp91phox and p22phox expression were examined by western blotting analysis in HUVECs and membrane translocation of p47phox and Rac-1 were investigated in HUVECs with membranes and cytosolic isolation. We found that the expression of p47phox and Rac-1 in membrane fractions were 2 3-fold higher in HUVECs stimulated with oxLDL for $1 \mathrm{hr}$ than those in control HUVECs (Figure 2A, 2B). The enhanced p47phox and Rac-1 on membrane translocation by oxLDL were inhibited by pretreatment with baicalein $(20 \mu \mathrm{M})$. Furthermore, we also confirmed that the total protein expression of gp91phox and p22phox were increased in endothelial cells stimulated to oxLDL for $24 \mathrm{hrs}$. As expected, pretreatment of oxLDL-stimulated HUVECs with baicalein $(2.5-20 \mu \mathrm{M})$ led to a reduction in gp91phox and p22phox protein expression. As well as, they were inhibited by NADPH oxidase inhibitor apocynin (Figure 2C, 2D).

\section{ROS generation and antioxidant enzyme expression}

Several lines of evidence implicate oxLDL increased production of ROS impairs endothelial function in humans, which subsequently cause to the endothelial dysfunction [18]. Therefore, we examined the influences of baicalein on the ROS formation (Figure 3A, 3B). The ROS concentrations significantly decreased in HUVECs which intervened with baicalein $(1.25-20 \mu \mathrm{M})$ and apocynin $(100$ $\mu \mathrm{M})$ for $2 \mathrm{hrs}$ followed by exposure to oxLDL $(150 \mu \mathrm{g} / \mathrm{ml})$ in a dose-dependent manner. In addition, LOX-1 antibody (LOX-1 ab) also inhibited oxLDL-caused ROS formation. 
Intracellular ROS are known to repress antioxidative enzymes. In Figure 3C and 3D, our data showed the protein levels of SOD-1 were suppressed by oxLDL stimulation and could be restored by baicalein treatment. However, oxLDL did not repress SOD-2 levels in endothelial cells.

\section{Effects of baicalein on oxLDL-induced protein kinase $C$ and $A M P K$ phosphorylation}

There is growing evidence indicated that oxLDLinduced PKC has been shown to contribute to the upregulation of NADPH oxidase as well as is dependent on AMPK regulation. We, therefore, investigate the effect of baicalein on AMPK and PKC activation to HUVECs induced by oxLDL. Our results showed that baicalein significantly increases AMPK phosphorylation in HUVECs (Figure 4A) and intervention of oxLDLstimulated HUVECs with baicalein $(2.5-20 \mu \mathrm{M})$ cause to significantly increase AMPK phosphorylation (Figure 4B, 4C). Stimulations of endothelial cells with oxLDL caused phosphorylation of protein kinase $\mathrm{C} \alpha$ and $\beta$ but not protein kinase $\gamma$ and $\delta$ within $1 \mathrm{hr}$ without affecting their protein levels (Figure 4D, 4E, 4F, 4G, 4H). Pretreatment with baicalein or AICAR reversed the oxLDL-induced phosphorylation of PKC $\alpha$ and $\beta$. Furthermore, this increase in PKC phosphorylation was not seen in cell pretreated with Compound $\mathrm{C}$ ( an inhibitor of AMPK) or AMPK knockdown (Figure 5).
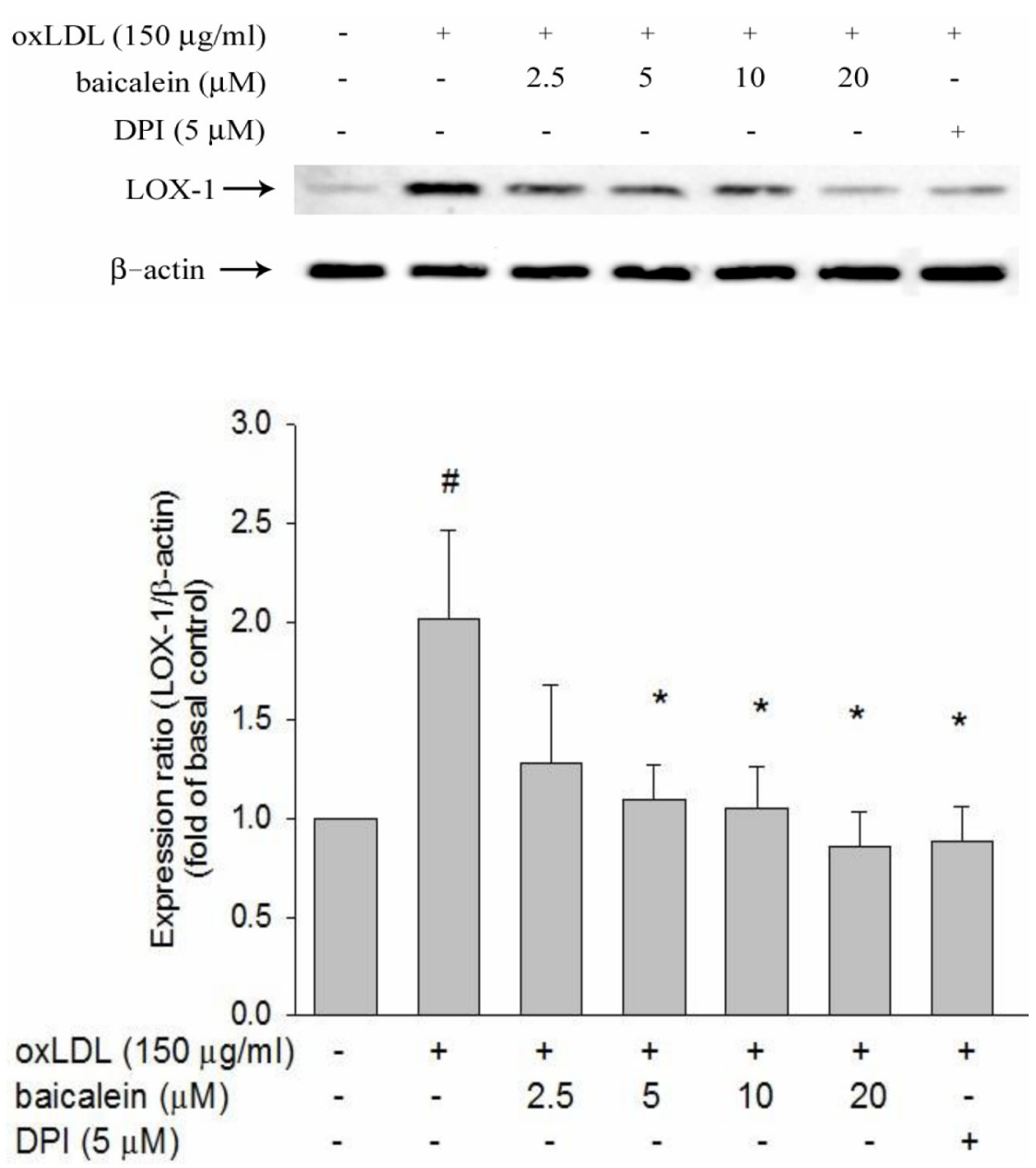

Figure 1: Inhibitory effects of baicalein on oxLDL-induced endothelial LOX-1(a lectin-like oxLDL receptor-1) protein expression. The expression of protein were analyzed by Western blot respectively pretreated with baicalein $(2.5-20 \mu \mathrm{M})$ or DPI $(5 \mu \mathrm{M})$ for $2 \mathrm{hrs}$ followed by exposure to oxLDL $(150 \mu \mathrm{g} / \mathrm{ml})$ for a further $24 \mathrm{hrs}$ period in HUVECs. The levels of LOX-1 protein were normalized to the level of $\beta$-actin. Data of bar figure represent mean \pm SEM of 3 independent analyses. $\# P<0.05$ compared with control and $* P<0.05$ compared with oxLDL-stimulated HUVECs. 
(A) $\begin{array}{rccccccc}\operatorname{oxLDL}(150 \mu \mathrm{g} / \mathrm{ml}) & - & + & + & + & + & + & + \\ \text { baicalein }(\mu \mathrm{M}) & - & - & 2.5 & 5 & 10 & 20 & - \\ \text { apocynin }(500 \mu \mathrm{M}) & - & - & - & - & - & - & +\end{array}$

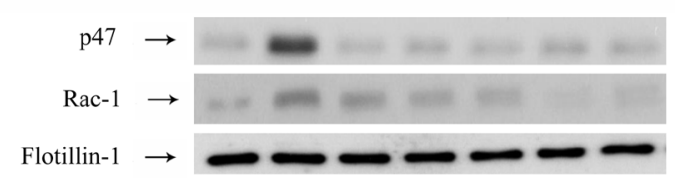

(B)

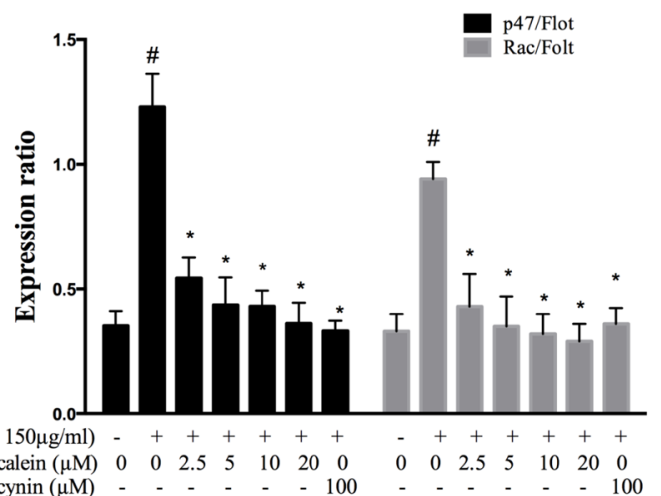

(C) $\begin{array}{rcccccccc}\text { oxLDL }(150 \mu \mathrm{g} / \mathrm{ml}) & - & + & + & + & + & + & + \\ \text { baicalein }(\mu \mathrm{M}) & - & - & 2.5 & 5 & 10 & 20 & - \\ \text { apocynin }(500 \mu \mathrm{M}) & - & - & - & - & - & - & +\end{array}$

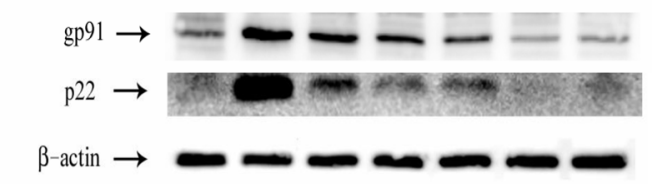

(D)

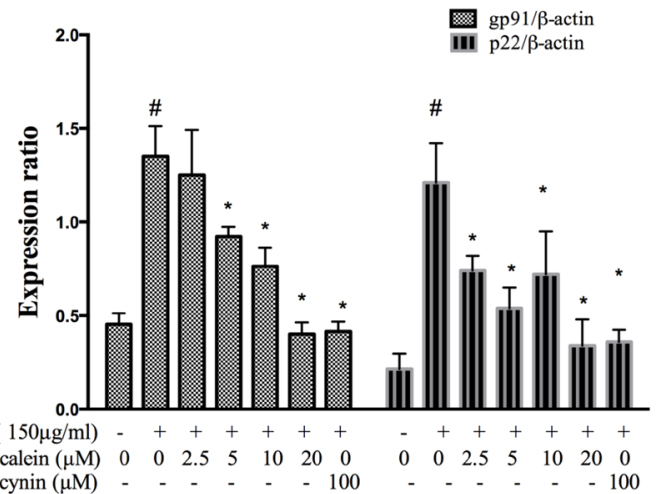

Figure 2: Baicalein attenuated the level of NADPH oxidase membrane assembly. HUVECs were pretreated for 2 hrs with the indicated concentrations of baicalein followed by stimulation with oxLDL $(150 \mu \mathrm{g} / \mathrm{mL})$ for $24 \mathrm{hrs}$. Representative Western blots A., C. and summary data B., D. showed that baicalein protected against oxLDL-induced p47phox and Rac-1 translocation to the plasma membrane, and gp91 as well as p22phox expression. The levels of cytosolic protein and membrane protein were normalized to the levels of $\beta$-actin and flotillin-1, respectively. Data are mean \pm SEM of three different experiments. $\# P<0.05$ compared with control and $* P<0.05$ compared with oxLDL-stimulated HUVECs.

(A)

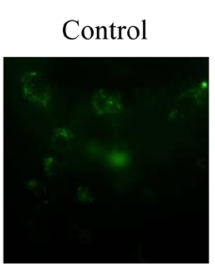

(B)
(C) oxLDL $(150 \mu \mathrm{g} / \mathrm{ml})$

baicalein $(\mu \mathrm{M})$

$\mathrm{Cu}, \mathrm{Zn}-\mathrm{SOD} \rightarrow$

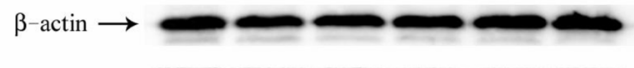

$\mathrm{Mn}-\mathrm{SOD} \rightarrow-\infty-\infty$

$\beta$-actin $\rightarrow$

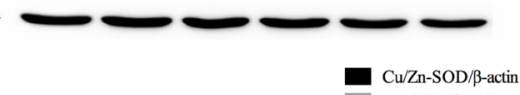

(D)

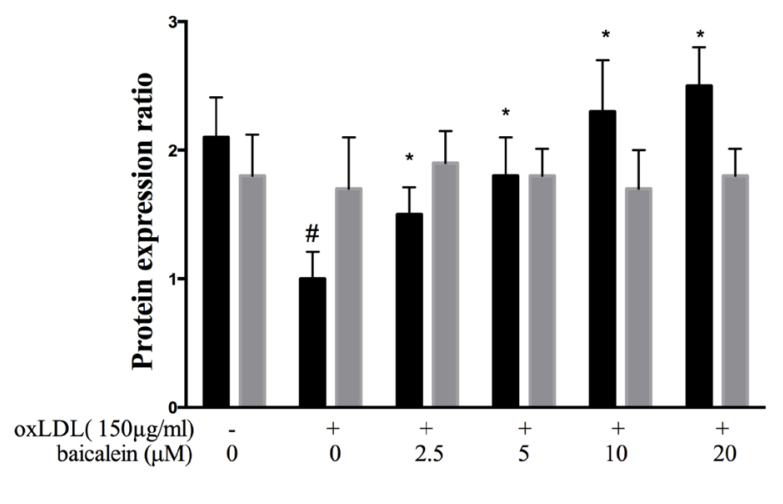

Figure 3: Inhibitory effects of baicalein on oxLDL-induced ROS generation in HUVECs. HUVECs were pretreated with baicalein $(2.5-20 \mu \mathrm{M})$ or apocynin $(100 \mu \mathrm{M})$ or LOX-1 antibody for $2 \mathrm{hrs}$ followed by $1 \mathrm{hr}$ incubation with fluorescent probe DCF-AM $(10 \mu \mathrm{M})$, oxLDL $(150 \mu \mathrm{g} / \mathrm{ml})$ was then added to medium for 2 hrs. A. Fluorescence images show the ROS level in control cells (left) and HUVECs stimulated with oxLDL alone (middle) and in the presence of $20 \mu \mathrm{M}$ baicalein (right). B. Fluorescence intensity of cells was measured with a fluorescence microplate reader. C., D. Rrepresentative of Western blot of Cu,Zn-SOD and Mn-SOD protein levels in HUVECs pretreated with baicalein $(2.5-20 \mu \mathrm{M})$ for $2 \mathrm{hrs}$, followed by $150 \mu \mathrm{g} / \mathrm{ml}$ oxLDL for $24 \mathrm{hrs}$. Data are mean \pm SEM of three different experiments. \# $P<0.05$ compared with control and $* P<0.05$ compared with oxLDL-stimulated HUVECs. 


\section{Baicalein protects against oxLDL-caused NADPH oxidase activation by modulation of AMPK and PKC}

In Figure 6, we found the expression levels of p47phox and Rac-1 in membrane fractions of endothelial cells were higher in HUVECs stimulated with oxLDL for $1 \mathrm{hr}$ than those in untreated HUVECs. Pretreatment with baicalein or AICAR mitigated the membrane shuttling of p47phox and Rac-1. Furthermore, this decrease in p47phox and Rac-1 membrane translocation was not seen in cell pretreated with Compound C or AMPK knockdown (Figure 6).

\section{Baicalein inhibits oxLDL-induced inflammation}

As shown in Figure $7 \mathrm{~A}-7 \mathrm{C}, \mathrm{NF}-\kappa \mathrm{Bp} 65$ protein expression levels were up-regulated and $\mathrm{I}-\mathrm{\kappa B}$ protein expression levels were down-regulated in oxLDLtreated endothelial nuclear fraction. However, this finding is restored by baicalein intervention. Next, we investigated whether baicalein represses NF- $\mathrm{kB}$-triggered downstream inflammatory proteins. As shown in Figure 7D, the expression of E-selectin, VCAM, ICAM were up-regulated in endothelial cells that had been stimulated with oxLDL for than in the non-treated HUVECs but not in cells which were pretreated with $20 \mu \mathrm{M}$ baicalein. As expected, Figure 7E shown that AMPK silencing impaired the ability of NF-kB reduction by baicalein.

\section{DISCUSSION}

Oxidized low density lipoprotein (oxLDL) in circulation system is one of well-known risk factors in human cardiovascular diseases [6]. The integrating of oxLDL to LOX-1 stimulates NADPH oxidase activation and quick increase intracellular ROS generation. Meanwhile, ROS accumulation in endothelial cell up-regulates LOX-1 expression. This present study showed that baicalein could suppress endothelial LOX1 protein expression due to suppressing ROS generation. Pretreatment with inhibitors of apocynin, PKC or antiLOX-1 mAb prevents oxLDL-facilitated superoxide
(A)

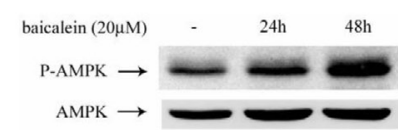

(B)

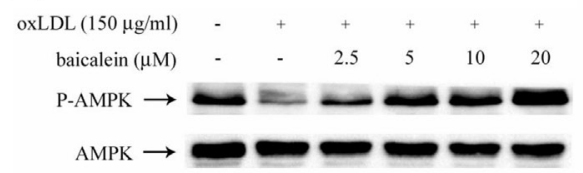

(C)

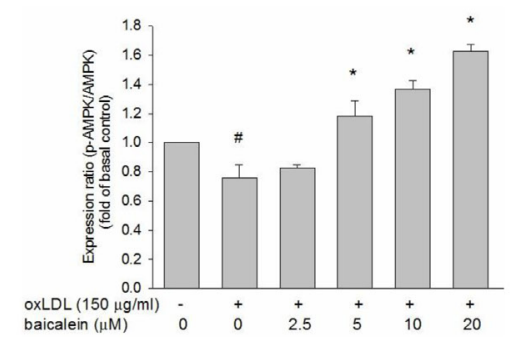

(D)

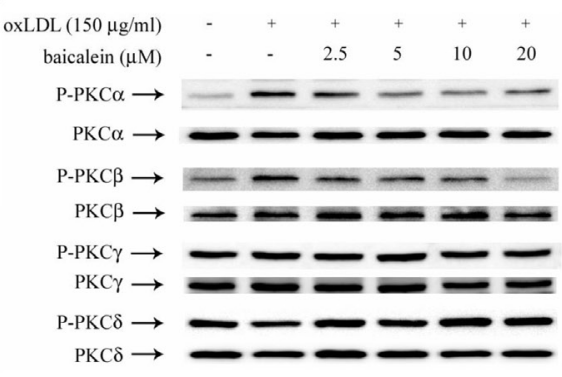

(E)

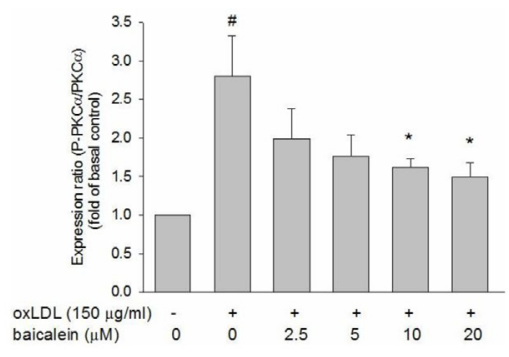

(F)

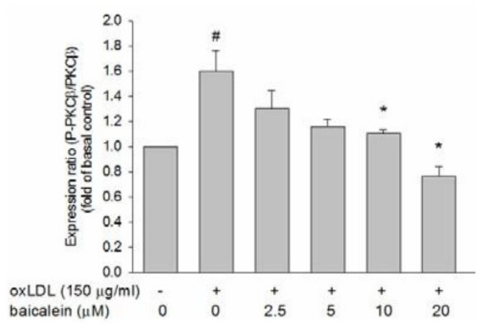

(G)

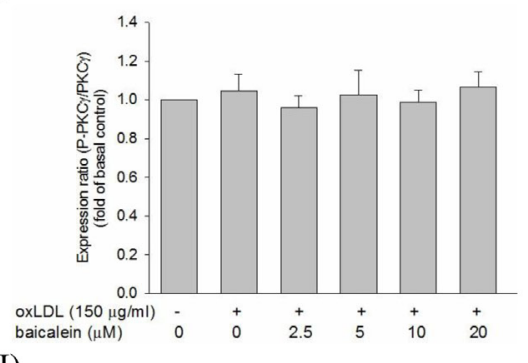

(H)

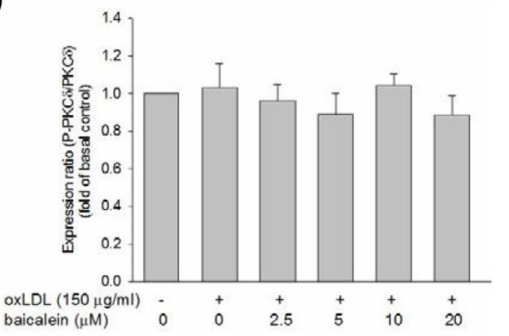

Figure 4: Effects of baicalein on oxLDL-impaired phosphorylation of AMPK and PKC activation in HUVECs. The level of AMPK phosphorylation in HUVECs were treated with baicalein $(20 \mu \mathrm{M})$ at $24 \mathrm{hrs}$ and $48 \mathrm{hrs}$ A. The protein expression of dephosphorylated and total AMPK were analyzed by Western blot pretreated with baicalein $(2.5-20 \mu \mathrm{M})$ for 2 hrs prior to exposure to oxLDL $(150 \mu \mathrm{g} / \mathrm{ml})$ in HUVECs. AMPK B., C. and PKC isoforms D., E., F., G., H. were analyzed by Western blot. Data of bar figure represent means \pm SEM of 3 independent analyses. $\# P<0.05$ compared with control and $* P<0.05$ compared with oxLDL-stimulated cells. 
(A)

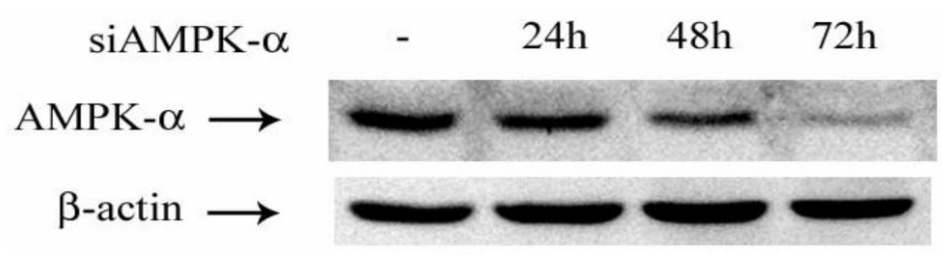

(B)

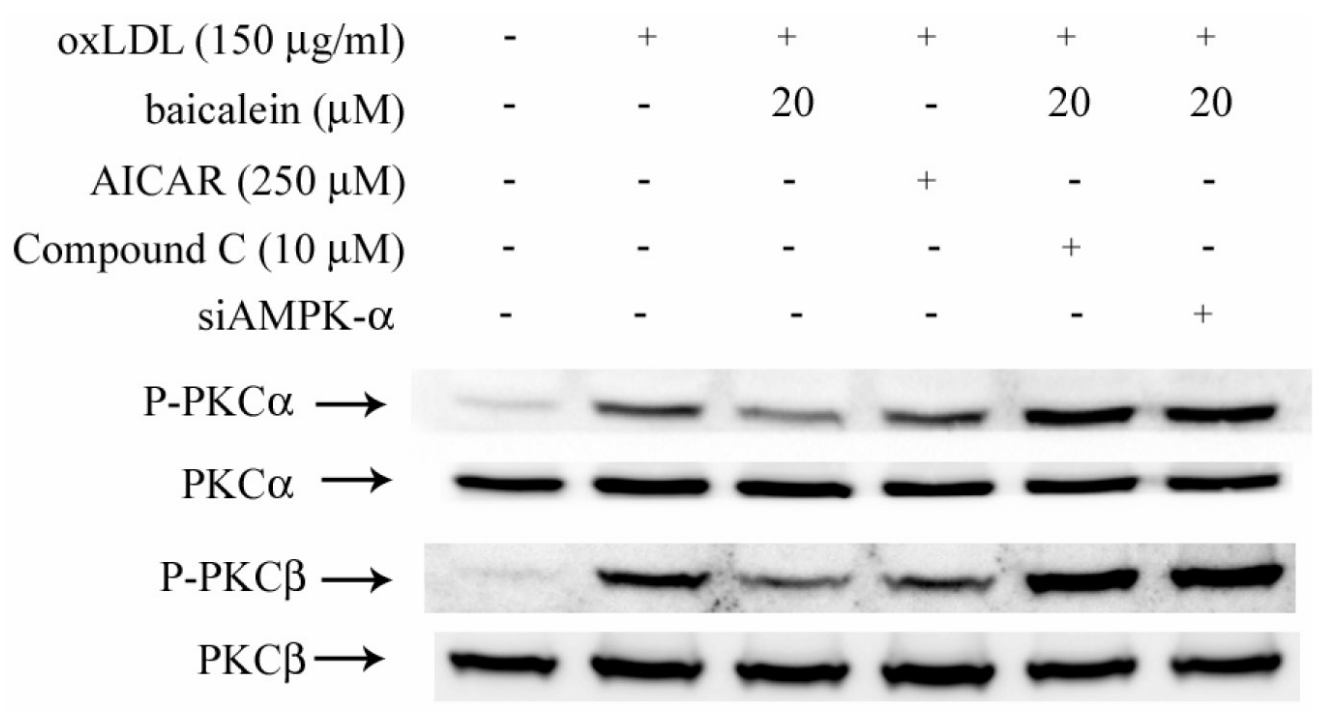

(C)

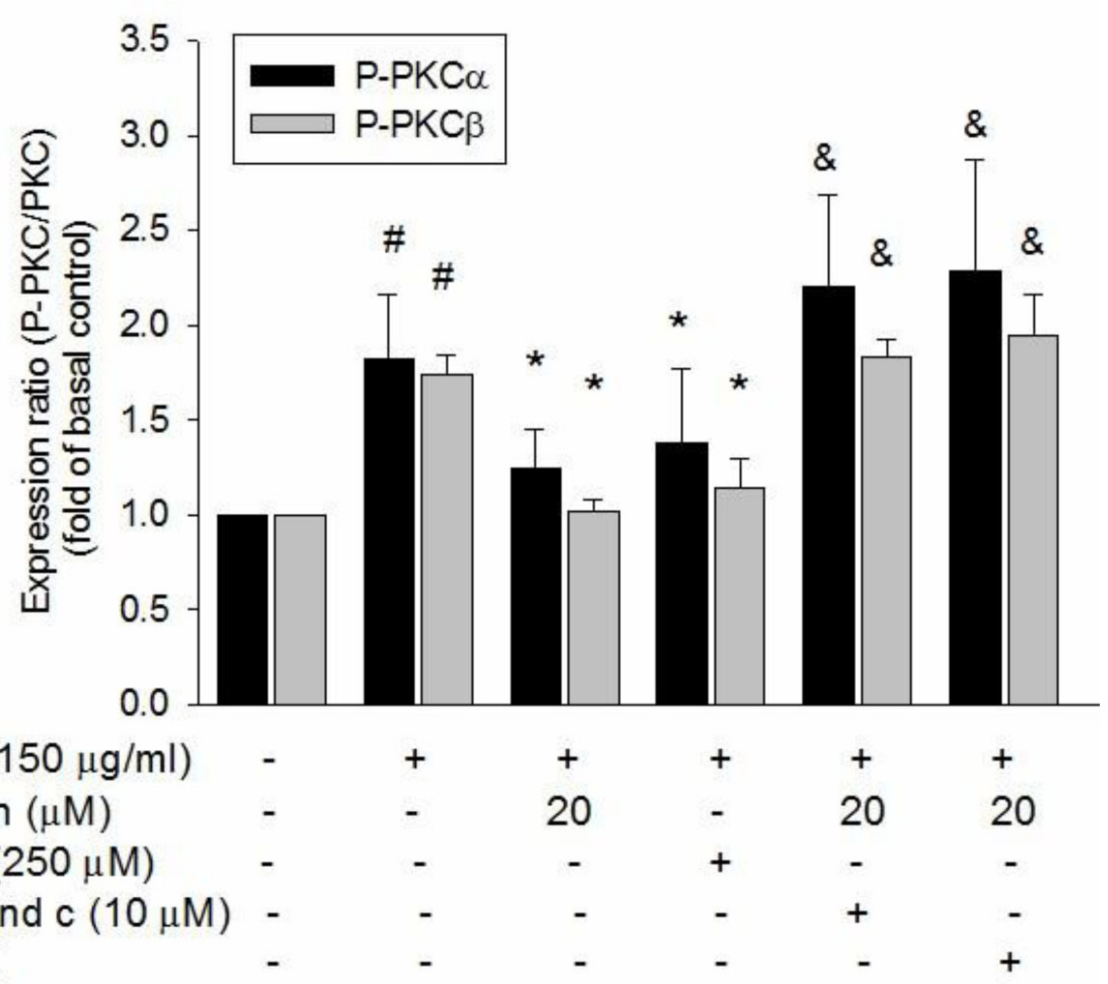

Figure 5: Effects of baicalein on oxLDL-induced phosphorylation of PKC $\alpha$ and PKC $\beta$. HUVECs were transfected with siAMPK- $\alpha$ or control scrambled siRNA. AMPK- $\alpha$ expression in siAMPK- $\alpha$ transfected cells at 24 hrs, 48 hrs, and 72 hrs A. The protein expression of phosphorylated and total PKC $\alpha$ and PKC $\beta$ were analyzed by Western blot pretreated with baicalein $(20 \mu \mathrm{M})$ or AICAR (250 $\mu \mathrm{M})$ for $2 \mathrm{hrs}$ and compound c $(10 \mu \mathrm{M})$ with baicalein $(20 \mu \mathrm{M})$ prior to exposure to oxLDL $(150 \mu \mathrm{g} / \mathrm{ml})$ for $1 \mathrm{hr}$ in HUVECs or pretreated with baicalein $(20 \mu \mathrm{M})$ in siAMPK-transfected HUVECs. $\# P<0.05$ compared with control, $\& P<0.05$ compared with baicalein and $* P<$ 0.05 compared with oxLDL-stimulated HUVECs. 
anion formation, suggesting that the integrating of oxLDL to LOX-1 and the consequent generation of red radical by NADPH oxidase via PKC may be the key procress in LOX-1 medicated endothelial injuries.

Vascular cells to oxidative stress is a operation of the equalization between the oxidative damage and the antioxidant defense capability [19]. Therefore, endothelial dysfunction caused by oxLDL resulted in ROS generation and antioxidant enzymes dysfunction, thereby induced endothelial death by triggering ROS-sensitive mechanism [20]. We found that baicalein intervention inhibited ROS formation and oxLDL-impaired SOD-1 levels (Figure 3). Therefore, we suggested that baicalein mitigates oxLDLinduced oxidative injuries could be through the increase the anti-oxidant enzymes activity and the capacity of ROS scavenging.

We assumed that the mechanisms by which baicalein inhibites oxLDL-caused endothelial dysfunction could be mainly through the ROS scavenger with SOD activity.

NADPH oxidase is the key origin of ROS generation in human vessel [21]. We found that intervention with a NADPH oxidase pharmacological inhibitor (apocynin)

(A)

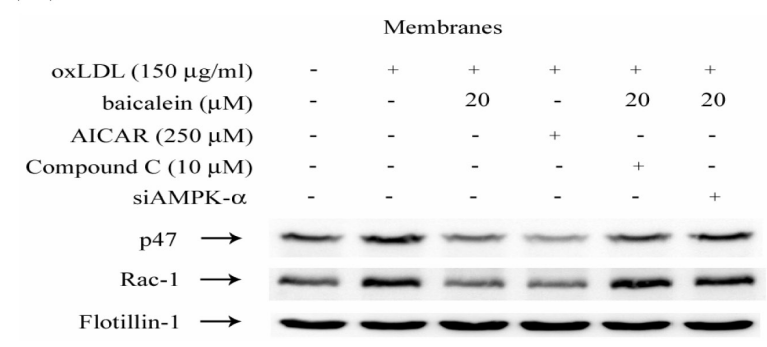

(B)

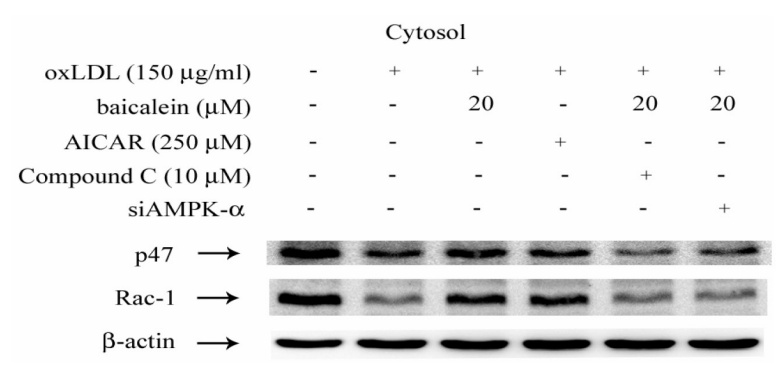

significantly suppressed oxLDL-induced ROS generation and baicalein also suppress oxLDL-induced NADPH oxidase protein expression and suppress the assembly of NADPH oxidase enzyme complex p47phox and Rac-1 membrane translocation. The present results showed that the pretreatment of HUVECs with baicalein abolished oxLDL-activated expression of NADPH oxidase and ROS production. A previous study showed high glucose causes ROS generation by NADPH oxidase is mediated by the DAG-PKC pathway in human endothelial cells. They also demonstrated that the inhibition of NADPH oxidasegenerated oxidative stress require the up-regulation of AMPK because this effect is completely abolished by Compound $\mathrm{C}$ (AMPK inhibitor) and enhanced by AICAR ( AMPK activator) [15]. And Li et al. suggested a mechanism for LOX-1 in oxLDL-caused MMP-1 and MMP-3 activation in endothelial cells are mediated by LOX-1 and PKC- $\beta$ signaling. They suggest that LOX1 induced NADPH oxidase activation is modulated by protein kinase $\mathrm{C}$ and NADPH oxidase-promoted endothelial dysfunction and MMPs expression is inhibited by AMPK [22]. Our study found that oxLDL can induce
(C)

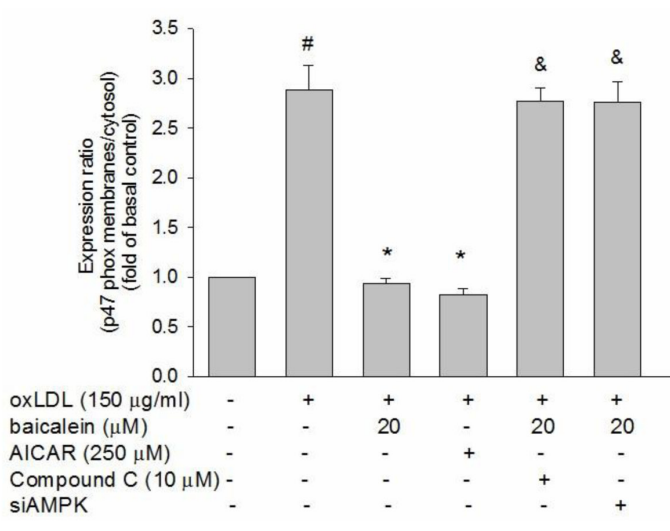

(D)

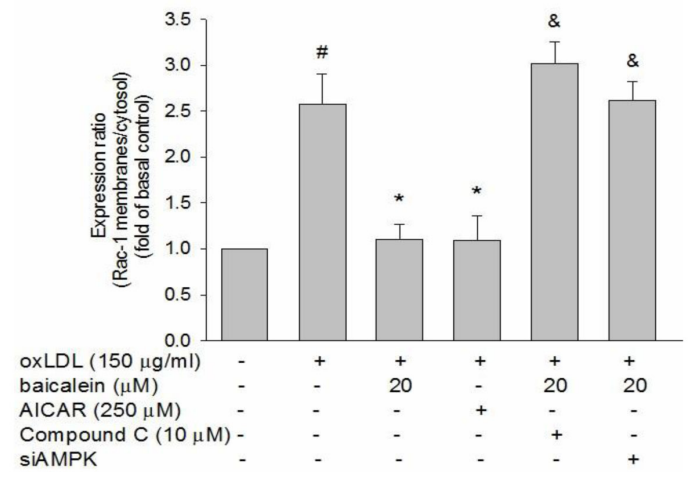

Figure 6: Effects of baicalein on oxLDL-induced subunit of NADPH oxidase complex p47phox and Rac-1 membrane translocation. The protein expression of $\mathrm{p} 47$ phox and Rac-1 were analyzed by Western blot pretreated with baicalein $(20 \mu \mathrm{M})$ or AICAR $(250 \mu \mathrm{M})$ for $2 \mathrm{hrs}$ and Compound $\mathrm{C}(10 \mu \mathrm{M})$ with baicalein $(20 \mu \mathrm{M})$ prior to exposure to oxLDL $(150 \mu \mathrm{g} / \mathrm{ml})$ for $1 \mathrm{hr}$ in HUVECs or pretreated with baicalein $(20 \mu \mathrm{M})$ in siAMPK-transfected HUVECs. Anti-flotillin-1 and anti- $\beta$-actin antibody were used for normalization of membranes and cytosolic proteins, respectively. Data of bar figure represent means \pm SEM of 3 independent analyses. $\# P<0.05$ compared with control, \& $P<0.05$ compared with baicalein $20 \mu \mathrm{M}$ and $* P<0.05$ compared with oxLDL-stimulated HUVECs. 
PKC- $\alpha$ and PKC- $\beta$ activation and is mitigated by AMPK (Figure 5). Incubation with baicalein significantly increased AMPK phosphorylation after 48 hrs in HUVECs (Figure 4). Pretreated with baicalein suppressed oxLDLinduced PKC- $\alpha$ and PKC- $\beta$ activation. The effects of baicalein suppressed PKC activation in oxLDL exposure cells are antagonized in the presence of Compound $\mathrm{C}$ or AMPK knockdown cells. Furthermore, pretreatment with AICAR reversed oxLDL-induced PKC activation (Figure 5). Thus, we strongly suggesting that baicalein attenuates oxLDL-induced protein kinase $\mathrm{C}$ and NADPH oxidase subunits $\mathrm{p} 47$ phox and Rac-1 membrane translocation is repressed by AMPK activation.

In summary, the present results indicated that baicalein attenuates LOX-1-mediated endothelial

(A)

(B)

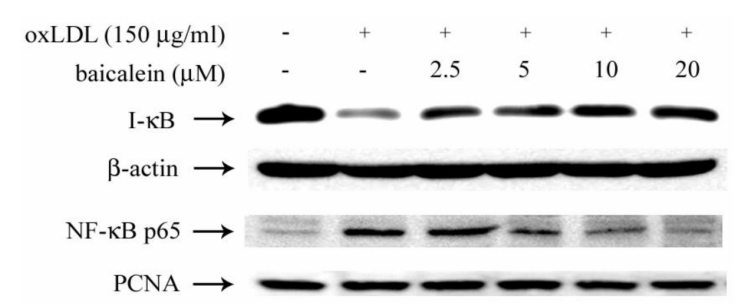

(C)
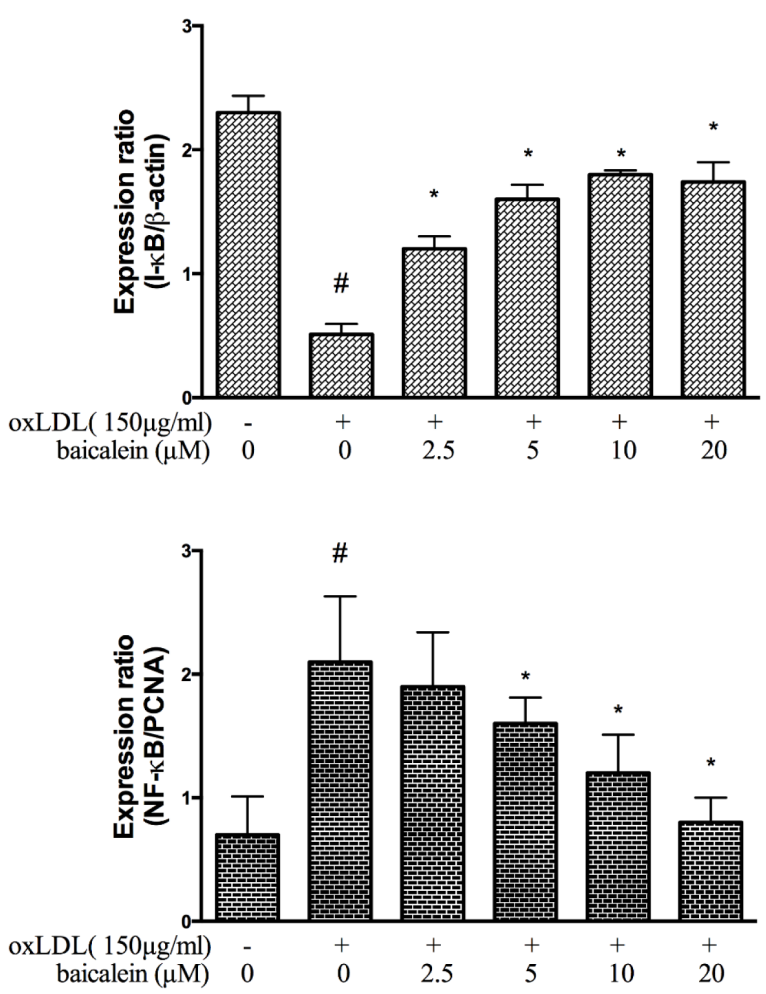

oxidative dysfunction via modulating AMPK / PKC / NADPH oxidase / NF- $\kappa$ B signaling. Therefore, reduce the downstream of NADPH oxidase-caused ROS formation and dysfunction of SOD-1. Our report adds to an evidence that baicalein has positive effects on human cardiovascular diseases.

\section{MATERIALS AND METHODS}

\section{Cell culture and reagents}

Human umbilical vein endothelial cells (HUVECs) were obtained from ATCC. HUVECs were cultured with M199 basal medium supplemented with low-

(D)

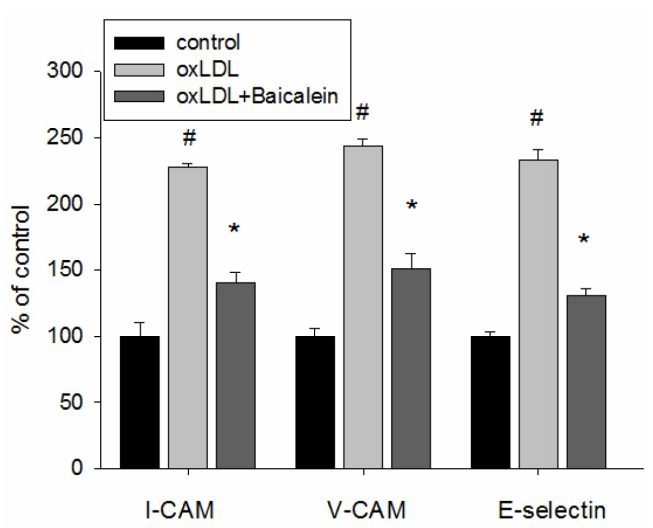

(E)

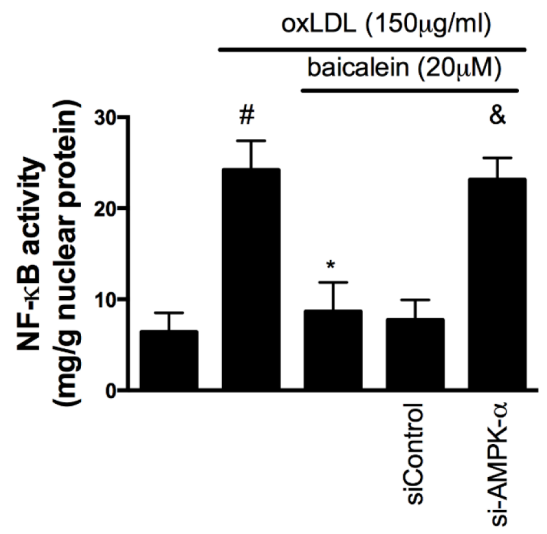

Figure 7: Effects of baicalein on oxLDL-induced NF-kB activation and adhesion molecular expression. A., B., C. The protein expression of cytosolic I $\kappa$ B and nucleus NF- $\kappa$ B were analyzed by Western blot pretreated with baicalein $(2.5-20 \mu \mathrm{M})$ for $2 \mathrm{hrs}$ prior to exposure to oxLDL $(150 \mu \mathrm{g} / \mathrm{ml})$ in HUVECs. Anti- $\beta$-actin and anti-PCNA antibody were used for normalization of cytosolic and nuclear proteins, respectively. control and $* P<0.05$ compared with oxLDL-stimulated HUVECs. D. The histogram of cell surface expression of VCAM-1, ICAM-1, and E-selectin was generated by flow cytometry. E. Nucleic proteins were extracted for nuclear translocation assay of NF-кBp65. Data are means \pm SEM of 3 independent analyses. \# $P<0.05$ compared with control, \& $P<0.05$ compared with baicalein 20 $\mu \mathrm{M}$ and $* P<0.05$ compared with oxLDL-stimulated HUVECs. 
serum growth supplement and penicillin (50 IU/ml)streptomycin $(50 \mu \mathrm{g} / \mathrm{ml})$. Trypsin-EDTA was used to passage cells. M199 and trypsin-EDTA were obtained from Gibco (Grand Island, NY, USA). Low-serum growth supplement was purchased from Cascade (Portland, OR, USA). Additionally. Baicalein, AICAR, Compound C, Apocynin, penicillin and streptomycin were all purchased from Sigma (St. Louis, MO, USA). Anti- $\beta$-actin, antiAMPK, anti-AMPK- $\alpha$, anti-phospho AKT, anti-LOX-1, anti-PKC $\alpha$, anti-PKC $\beta$, anti-PKC $\gamma$, anti-PKC $\delta$, I- $\mathrm{KB}$, NF$\kappa B p 65$, anti-Cu,Zn SOD, anti-Mn SOD were all obtained from Santa Cruz Biotechnology (Santa Cruz, CA, USA).

\section{Lipoprotein separation}

Human plasma was obtained from the Taichung Blood Bank (Taichung, Taiwan) and LDL was isolated using sequential ultracentrifugation $(=1.019-1.063 \mathrm{~g} / \mathrm{ml})$ in $\mathrm{KBr}$ solution containing $30 \mathrm{mM}$ EDTA, stored at $4{ }^{\circ} \mathrm{C}$ in sterile, dark environment and used within 3 days as previously described. Immediately before the oxidation tests, LDL was separated from EDTA and from diffusible low molecular mass compounds by gel filtration on PD-10 Sephadex G-25 Mgel (Pharmacia) in $0.01 \mathrm{~mol} / 1$ phosphate-buffered saline $(136.9 \mathrm{mmol} / \mathrm{l} \mathrm{NaCl}, 2.68$ $\mathrm{mmol} / \mathrm{l} \mathrm{KCl}, 4 \mathrm{mmol} / \mathrm{l} \mathrm{Na} 2 \mathrm{HPO} 4,1.76 \mathrm{mmol} / \mathrm{l} \mathrm{KH} 2 \mathrm{PO} 4)$ at $\mathrm{pH}$ 7.4. $\mathrm{Cu} 2+$-modified LDL ( $1 \mathrm{mg}$ protein $/ \mathrm{ml}$ ) was prepared by exposing LDL to $10 \mu \mathrm{M} \mathrm{CuSO} 4$ for $16 \mathrm{hrs}$ at $37^{\circ} \mathrm{C}$. Protein concentration was determined by Bradford Protein Assay.

\section{Measurement of ROS production}

The effect of baicalein on ROS production in HUVECs was determined by a fluorometric assay using 2',7'-dichlorofluorescein acetoxymethyl ester (DCFAM). Confluent HUVECs $\left(10^{4}\right.$ cells/well $)$ in 96-well plates were preincubated with various concentrations of baicalein for $2 \mathrm{hrs}$; After the removal of medium from wells, cells were incubated with $10 \mu \mathrm{M}$ DCF-AM for 1 hr. oxLDL was then added to the medium in the absence or presence of baicalein for $2 \mathrm{hrs}$. The fluorescence intensity was measured with a fluorescence microplate reader (Labsystem, CA) calibtated for exciation at 485 $\mathrm{nm}$ and emission at $538 \mathrm{~nm}$. The percentage increase in fluorescence per well was calculated by the formula [(Ft2$\mathrm{Ft} 0) / \mathrm{Ft} 0] \mathrm{X} \mathrm{100,}$, where $\mathrm{Ft} 2$ is the fluorescence at $2 \mathrm{hrs}$ of oxLDL exposure and Ft0 is the fluorescence at $0 \mathrm{~min}$ of oxLDL exposure.

\section{Immunoblotting}

To determine whether baicalein could ameliorate the oxLDL-induced protein. HUVECs were grown to confluence, pretreated with baicalein for $2 \mathrm{hrs}$ and then stimulated with oxLDL for $24 \mathrm{hrs}$. At the end of stimulation, cells were washed, scraped from dishes, and lysed in RIPA buffer (in mM: HEPES 20, $\mathrm{MgCl} 21.5$, EDTA 2, EGTA 5, dithiothreitol 0.1, phenylmethylsulfonyl fluoride $0.1, \mathrm{pH} 7.5)$. Proteins $(30 \mu \mathrm{g})$ were separated by electrophoresis on SDS-polyacrylamide gel. After the protein had been transferred to polyvinylidene difluoride membrane (Millipore, Bedford, MA), the blots was incubated with blocking buffer (1X PBS and 5\% nonfat dry milk) for $1 \mathrm{hr}$ at room temperature and then probed with primary antibodies overnight at $4{ }^{\circ} \mathrm{C}$, followed by incubation with horseradish peroxidase-conjugated secondary antibody (1:5000) for $1 \mathrm{hr}$. To control equal loading of total protein in all lanes, blots were stained with mouse anti- $\beta$-actin antibody at a 1:50000 dilution. The bound immunoproteins were detected by an enhancer chemiluminescent assay (ECL; Amersham, Berkshire, UK). The intensities were quantified by densitometric analysis (Digital Protein DNA Imagineware, Huntington Station, NY).

\section{AMPK silencing}

The day before the experiment, the cells were harvested by trypsinization, resuspended in complete medium at the concentration of $1 \times 10^{5}$ cells $/ \mathrm{mL}$, and kept at $37^{\circ} \mathrm{C}$, while the transfection complex was being prepared. Gene silencing of AMPK was performed by specific synthesized siRNA for AMPK $\alpha 1$ (validated siRNA, Santa Cruz, CA, USA). The day of the experiment, transfection siRNA (10 nM) or scrambled sequence as control was incubated with Polyplus Transfection Reagent (Qiagen, Hilden, Germany) following manufacturer's instructions. After $10 \mathrm{~min}$ incubation at room temperature, the obtained complexes were added drop-wise onto the cells subcultured in replaced culture medium. The cells were maintained in a $37^{\circ} \mathrm{C}$ incubator until analysis. After $24 \mathrm{hrs}$, $48 \mathrm{hrs}$ and $72 \mathrm{hrs}$ from transfection, the cells were collected for protein and gene expression analyses of AMPK. Cell viability of all the samples exceeded $80 \%$.

\section{Membrane protein extraction}

We used Mem-PER ${ }^{\circledR}$ Eukaryotic Membrane Protein Extraction Reagent Kit to extract membrane protein. Cells grown to $80 \%$ confluency and subjected to various treatments were subsequently washed with ice-cold PBS and it was prepared for membrane protein extraction. Cells grown on $10-\mathrm{cm}$ dish gently scraped with $3 \mathrm{ml}$ ice-cold PBS and it was centrifuged at 10,000x g for 10 min at $4^{\circ} \mathrm{C}$. After carefully aspirating the supernatant, cells added $150 \mu 1$ of Reagent A to the cell pellet. Pipette up and down to obtain a homogeneous cell suspension. Incubate 10 minutes at room temperature with occasional 
vortexing, then added $450 \mu \mathrm{l}$ of diluted Reagent $\mathrm{C}$ to each tube of lysed cells and vortex. Incubate tubes on ice for 30 minutes, vortexing every 5 minutes. Centrifuge tubes at $10,000 \mathrm{x}$ g for 3 minutes at $4^{\circ} \mathrm{C}$. Transfer supernatant to new tubes and incubate 10 minutes in $37^{\circ} \mathrm{C}$ water bath to separate the membrane protein fraction. Centrifuge tubes at room temperature for 2 minutes at $10,000 \mathrm{~g}$ to isolate the hydrophobic fraction (i.e., the fraction containing membrane protein of interest) from the hydrophilic fraction, Carefully remove the hydrophilic phase (top layer) from the hydrophobic protein phase (bottom layer) and save in a new tube. Perform phase separations as quickly as possible because the interface between the layers slowly disappears at room temperature. Place the separated fractions on ice. The supernatants (membrane protein extracts) were stored aliquots at $-80^{\circ} \mathrm{C}$. Protein concentration of the supernatants were determined by the colorimetric assay (Bradford).

\section{Nuclear protein extraction}

Cells grown to $80 \%$ confluency and subjected to various treatments were subsequently washed with ice-cold PBS and it was prepared for nuclear protein extraction. Cells grown on $10-\mathrm{cm}$ dish were gently scraped with $3 \mathrm{ml}$ ice-cold PBS and it were centrifuged at $1,000 \mathrm{x}$ g for $10 \mathrm{~min}$ at $4^{\circ} \mathrm{C}$. After carefully aspirating the supernatant, cells were resuspended with $200 \mu \mathrm{l}$ icecold BUFFER-I (10 mM Hepes (pH 8.0), $1.5 \mathrm{mM} \mathrm{MgCl2,}$ $10 \mathrm{mM} \mathrm{KCl}, 1 \mathrm{mM}$ dithiothreitol, and proteinase inhibitor cocktail (Roche Molecular Biochemicals) and incubated for $15 \mathrm{~min}$ on ice to allow cells to swell, followed by adding 2011 IGEPAL-CA630. After vigorously vortexing for $10 \mathrm{~s}$ and centrifuging at $16,000 \mathrm{~g}$ for $5 \mathrm{~min}$ at $4^{\circ} \mathrm{C}$, the supernatant (cytoplasmic fraction) were carefully aspirated and the pellet were resuspended with ice-cold BUFFER-II (20 mM Hepes ( $\mathrm{pH} 8.0$ ), $1.5 \mathrm{mM} \mathrm{MgCl2}$, 25\% glycerol, $420 \mathrm{mM} \mathrm{NaCl}, 0.2 \mathrm{mM}$ EDTA, $1 \mathrm{mM}$ dithiothreitol and proteinase inhibitor cocktail (Roche Molecular Biochemicals)) and vigorously vortex. After vortexing, the suspension was placed on ice for $30 \mathrm{~min}$ before centrifuging at $16,000 \mathrm{x}$ g for $15 \mathrm{~min}$ at $4^{\circ} \mathrm{C}$. The supernatants (nuclear extracts) were stored aliquots at $-80^{\circ} \mathrm{C}$. Protein concentration of the supernatants was determined by the colorimetric assay (Bradford). NF$\kappa \mathrm{B}$ activity was measured by an NF- $\kappa \mathrm{B}$ p65 Active ELISA kit (Imgenex, San Diego, CA) according to the manufacturer's instructions. The absorbance at $405 \mathrm{~nm}$ was determined using a microplate reader (spectraMAX 340).

\section{Adhesion molecule expression}

To determine whether baicalein could modify the oxLDL-induced adhesion molecule expression, HUVECs were grown to confluence, pretreated with baicalein for $2 \mathrm{hrs}$ and stimulated with oxLDL $(150 \mu \mathrm{g} / \mathrm{ml})$ for 24 hrs. At the end of stimulation, HUVECs were harvested and incubated with FITC-conjugated anti-ICAM-1, antiVCAM-1 and anti-E-selectin (R\&D, Minneapolis, MN) for $45 \mathrm{~min}$ at room temperature. After the HUVECs had been washed three times, their immunofluorescence intensity was analyzed by flow cytometry using a Becton Dickinson FACScan flow cytometer (Mountain View, CA, USA).

\section{Statistical analyses}

All experiments were repeated 3 times, and one of these results is provided. Results are expressed as mean \pm SEM. Differences between the groups were analyzed using one-way ANOVA followed by the Student's t test. A P-value $<0.05$ was considered statistically significant.

\section{ACKNOWLEDGMENTS}

This study was supported by grants from the Ministry of Science and Technology (MOST-1052311-B-006 -008 and MOST 105-2320-B-039-003-MY2) and National Cheng Kung University (D105-35A06). NCKUH-10507011 and NCKUH-10408024 from National Cheng Kung University Hospital. CMU105-S-45 from China Medical University.

\section{CONFLICTS OF INTEREST}

The authors have declared no conflict of interest.

\section{REFERENCES}

1. Madamanchi NR, Vendrov A and Runge MS. Oxidative stress and vascular disease. Arteriosclerosis, thrombosis, and vascular biology. 2005; 25:29-38.

2. Bird DA, Gillotte KL, Horkko S, Friedman P, Dennis EA, Witztum JL and Steinberg D. Receptors for oxidized low-density lipoprotein on elicited mouse peritoneal macrophages can recognize both the modified lipid moieties and the modified protein moieties: implications with respect to macrophage recognition of apoptotic cells. Proceedings of the National Academy of Sciences of the United States of America. 1999; 96:6347-6352.

3. Brevetti G, Schiano V and Chiariello M. Endothelial dysfunction: a key to the pathophysiology and natural history of peripheral arterial disease? Atherosclerosis. 2008; 197:1-11.

4. Hung CH, Chan SH, Chu PM and Tsai KL. Quercetin is a potent anti-atherosclerotic compound by activation of SIRT1 signaling under oxLDL stimulation. Molecular 
nutrition \& food research. 2015; 59:1905-1917.

5. Glass CK and Witztum JL. Atherosclerosis. the road ahead. Cell. 2001; 104:503-516.

6. Azumi H, Inoue N, Takeshita S, Rikitake Y, Kawashima $\mathrm{S}$, Hayashi $\mathrm{Y}$, Itoh $\mathrm{H}$ and Yokoyama M. Expression of NADH/NADPH oxidase p22phox in human coronary arteries. Circulation. 1999; 100:1494-1498.

7. Schlesinger PH, Gross A, Yin XM, Yamamoto K, Saito M, Waksman G and Korsmeyer SJ. Comparison of the ion channel characteristics of proapoptotic BAX and antiapoptotic BCL-2. Proceedings of the National Academy of Sciences of the United States of America. 1997; 94:11357-11362.

8. Yoshida H, Kondratenko N, Green S, Steinberg D and Quehenberger O. Identification of the lectin-like receptor for oxidized low-density lipoprotein in human macrophages and its potential role as a scavenger receptor. The Biochemical journal. 1998; 334 :9-13.

9. Murphy JE, Tacon D, Tedbury PR, Hadden JM, Knowling S, Sawamura T, Peckham M, Phillips SE, Walker JH and Ponnambalam S. LOX-1 scavenger receptor mediates calcium-dependent recognition of phosphatidylserine and apoptotic cells. The Biochemical journal. 2006; 393:107115.

10. Kakutani M, Masaki $\mathrm{T}$ and Sawamura T. A plateletendothelium interaction mediated by lectin-like oxidized low-density lipoprotein receptor-1. Proceedings of the National Academy of Sciences of the United States of America. 2000; 97:360-364.

11. Moriwaki H, Kume N, Sawamura T, Aoyama T, Hoshikawa H, Ochi H, Nishi E, Masaki T and Kita T. Ligand specificity of LOX-1, a novel endothelial receptor for oxidized low density lipoprotein. Arteriosclerosis, thrombosis, and vascular biology. 1998; 18:1541-1547.

12. Dandapat A, Hu C, Sun L and Mehta JL. Small concentrations of oxLDL induce capillary tube formation from endothelial cells via LOX-1-dependent redox-sensitive pathway. Arteriosclerosis, thrombosis, and vascular biology. 2007; 27:2435-2442.

13. Fisslthaler B and Fleming I. Activation and signaling by the AMP-activated protein kinase in endothelial cells. Circulation research. 2009; 105:114-127.
14. Wang S, Zhang M, Liang B, Xu J, Xie Z, Liu C, Viollet B, Yan D and Zou MH. AMPKalpha2 deletion causes aberrant expression and activation of $\mathrm{NAD}(\mathrm{P}) \mathrm{H}$ oxidase and consequent endothelial dysfunction in vivo: role of $26 \mathrm{~S}$ proteasomes. Circulation research. 2010; 106:1117-1128.

15. Ceolotto G, Gallo A, Papparella I, Franco L, Murphy E, Iori E, Pagnin E, Fadini GP, Albiero M, Semplicini A and Avogaro A. Rosiglitazone reduces glucose-induced oxidative stress mediated by NAD(P)H oxidase via AMPKdependent mechanism. Arteriosclerosis, thrombosis, and vascular biology. 2007; 27:2627-2633.

16. Huang Y, Tsang SY, Yao X and Chen ZY. Biological properties of baicalein in cardiovascular system. Current drug targets Cardiovascular \& haematological disorders. 2005; 5:177-184.

17. Li-Weber M. New therapeutic aspects of flavones: the anticancer properties of Scutellaria and its main active constituents Wogonin, Baicalein and Baicalin. Cancer treatment reviews. 2009; 35:57-68.

18. Salvayre R, Auge N, Benoist H and Negre-Salvayre A. Oxidized low-density lipoprotein-induced apoptosis. Biochimica et biophysica acta. 2002; 1585:213-221.

19. Higashi $Y$, Noma $K$, Yoshizumi $M$ and Kihara $Y$. Endothelial function and oxidative stress in cardiovascular diseases. Circulation journal. 2009; 73:411-418.

20. Tsai KL, Chen LH, Chiou SH, Chiou GY, Chen YC, Chou HY, Chen LK, Chen HY, Chiu TH, Tsai CS, Ou HC and Kao CL. Coenzyme Q10 suppresses oxLDL-induced endothelial oxidative injuries by the modulation of LOX1-mediated ROS generation via the AMPK/PKC/NADPH oxidase signaling pathway. Molecular nutrition \& food research. 2011; 55 Suppl 2:S227-240.

21. Griendling KK, Sorescu D, Lassegue B and UshioFukai M. Modulation of protein kinase activity and gene expression by reactive oxygen species and their role in vascular physiology and pathophysiology. Arteriosclerosis, thrombosis, and vascular biology. 2000; 20:2175-2183.

22. Li D, Liu L, Chen H, Sawamura T, Ranganathan S and Mehta JL. LOX-1 mediates oxidized low-density lipoprotein-induced expression of matrix metalloproteinases in human coronary artery endothelial cells. Circulation. 2003; 107:612-617. 